\title{
Mahara como red social y portafolio digital en los nuevos contextos de formación inicial docente. Un estudio de caso
}

\section{Mahara as a social network and digital portfolio in the new contexts of initial teacher training. A case Study}

\author{
Laura de la Concepción Muñoz González \\ Universidad de Málaga, Málaga, España \\ lauramglez@uma.es \\ Encarna Soto Gómez \\ Universidad de Málaga, Málaga, España \\ esoto@uma.es
}

\begin{abstract}
Resumen
El objetivo de esta investigación es comprender las virtualidades y limitaciones de la red social y portafolio digital Mahara en la formación inicial docente. En los últimos años, los medios digitales, entre los que destacan las redes sociales, han incrementado su influencia en los distintos ámbitos de la vida cotidiana. Las aulas, ocupadas ya por nativos digitales, ponen de manifiesto la necesidad de incorporar en la educación herramientas que permitan transferir las funcionalidades que tanto nos atraen de las redes sociales (interactividad, sociabilidad, facilidad para crear espacios de intimidad, personalización y acceso a información ilimitada) al ámbito académico, especialmente en la formación del profesorado novel. En este sentido, se ha llevado a cabo un estudio de caso conformado por un grupo de estudiantes de Educación Infantil de la Universidad de Málaga y su profesorado, quienes utilizan Mahara en varias asignaturas. El análisis y triangulación de los datos dio lugar a siete categorías emergentes que nos permiten conocer las potencialidades y desafíos de la herramienta a través de la singularidad de lo que podría considerarse como una buena experiencia formativa. Estos resultados muestran como Mahara ayuda a promover el desarrollo de competencias docentes a través de la integración de lo formal y lo social.
\end{abstract}

\section{Palabras clave}

Formación docente, redes sociales, portafolio digital, evaluación formativa, estudio de caso.

\begin{abstract}
The objective of this research is to understand the virtualities and limitations of the Mahara social network and digital portfolio in initial teacher training. In recent years, digital media, among which social networks stand out, have increased their influence in different areas of daily life. The classrooms, already occupied by digital natives, highlight the need to incorporate into education tools that allow transferring the functionalities that attract us so much from social networks (interactivity, sociability, ease to create spaces of intimacy, personalization and access to information unlimited) to the academic field, especially in the training of new teachers.. In this sense, a case study has been carried out consisting of a group of students of Early Childhood Education of the University of Malaga and its teaching staff, who use Mahara in various subjects. The analysis and triangulation of the data gave rise to seven emerging categories that allow us to understand the potential and challenges of the tool through the uniqueness of what could be considered as a good teacher training experience. These results show how Mahara helps promote the development of teaching competencies through the integration of the formal and the social.
\end{abstract}

Keywords

Teacher training, social network, ePortfolio, formative evaluation, case study. 


\section{Introducción}

Los medios digitales han pasado a formar parte ineludible de la vida diaria, transformando nuestra manera de ser y estar en el mundo. Dispositivos móviles, tabletas electrónicas, relojes inteligentes, ordenadores de escritorio, portátiles, etc. han alterado el tradicional devenir analógico para sumergirnos en un escenario digitalizado de alcances y ecos inciertos. Rodríguez (2019) nos habla del hommo digitalis, los primitivos de una nueva era, profundamente apegados y dependientes de las nuevas tecnologías.

"Nada ni nadie queda exento del profundo efecto transformador que la mutación de las tecnologías de la comunicación tiene sobre nosotros, sobre nuestra percepción, sobre nuestra manera de relacionarnos socialmente, sobre la construcción de nuestra misma identidad, sobre nuestra idea de lo que es conocimiento y la forma en que debemos adquirirlo, sobre las industrias que crecieron utilizándola y desarrollándola" (p. 179).

Pero ante la infinitud de innovaciones y su influyente proyección, las redes sociales digitales destacan muy especialmente, siendo la causa de una auténtica revolución en el campo de las relaciones y la comunicación. No solo nos ofrecen nuevos canales y códigos, sino que además superan la presencialidad, permiten la construcción de una identidad digital deliberada y aceleran la difusión de la información y el conocimiento. Estudios como el de We are social y Hootsuite (2019), señalan que los jóvenes de entre 13 y 17 años ya conforman, en algunas plataformas como Snapchat, el 17\% de usuarios registrados (p. 127). Asimismo, los adultos de entre 18 y 34 años representan al 59\%, de participantes registrados en las redes sociales más populares (p. 74). Estos datos revelan la existencia de una realidad digital cuasi paralela, influyente y significativa.

Llegados a este punto, parece preciso preguntarse si esta digitalización ha sido acogida por la enseñanza, en qué medida puede beneficiar el aprendizaje y, no menos importante, ¿cómo se están abordando estos nuevos contextos desde la formación inicial docente?

\subsection{La realidad digital: Cambios sociales que entrañan cambios educativos}

Nadie podría negar que vivimos sumidos en una auténtica realidad digital, definida por Deloitte Insights (2019) como aquel escenario en el que confluyen tecnologías de realidad aumentada, realidad virtual, realidad mixta, $360^{\circ}$ y tecnologías inmersivas. Un entorno tridimensional que contiene experiencias de la vida real, donde el ser humano participa e interactúa, decidiendo cómo, cuándo, dónde y ante quién muestra información y reacciona. Se trata de un nuevo contexto que, en 2018, produjo 3,7 millones de búsquedas en Google por minuto, el envío de 38 millones de WhatsApp, 18 millones de mensajes de texto, 187 millones de email y 481.000 tweets (Desjardins, 2018).

Ante tal vorágine tecnológica, las redes sociales, caracterizadas por su cómoda interactividad, personalización, sociabilidad, facilidad para crear espacios de intimidad y acceso a información ilimitada (Izco, 2007, p. 284-290), constituyen una pieza clave de este nuevo constructo social. 
En este sentido, el Pew Research Center (2015) publicó un estudio desarrollado en EEUU entre 2005-2015 cuyos resultados fueron bastante concluyentes: en la última década, el número de personas que utilizan las redes sociales ha aumentado exponencialmente, pasando del $7 \%$ al $65 \%$. No se trata de una investigación aislada, en la misma línea concurren los resultados del IX Estudio Redes Sociales IAB Spain (2019) donde se revela que el 85\% de internautas españoles de entre 16 y 65 años utilizan redes sociales, es decir, 25.5 millones de usuarios en nuestro país. Asimismo, en los diez últimos años, las plataformas en línea para relacionarnos también se han multiplicado, siendo Youtube (85\%), WhatsApp (87\%), Facebook (82\%), Instagram (54\%) y Twitter (49\%), las más populares en España (Digital 2019).

Esta moderna manera de acceder a la información y comunicarnos, configura nuevas formas de pensar, expresar, actuar e incluso producir. Tal es así que el Informe de Infoempleo-Adecco (2018) sobre Redes Sociales y Mercado de Trabajo en España, señaló que entre los medios utilizados para buscar nuevos candidatos a un trabajo, las Redes Sociales representaban el 72,44\%, siendo utilizadas, de igual modo, por parte de los usuarios en activo $(79,8 \%)$ o inactivos $(80,6 \%)$ para buscar empleo. Asimismo, tampoco podemos olvidarnos de otras herramientas digitales como los blog, facilitada por servidores como Blogger o Wordpress. Según un estudio llevado cabo por IAB España (2015), el 49\% de usuarios de internet la utilizan como fuente de información y principal influencia para su compra online. Asimismo, en marzo de 2019, Wordpress era usado por un 60,3\% de sitios basados en gestores de contenidos (W3Techs, 2019).

Sin embargo, esta abundancia de información y accesibilidad infinita representa un influjo nada ingenuo para los gigantes de internet como Google, Yahoo, Apple, Microsoft o Amazon, quienes estudian los más mínimos movimientos de cada usuario, archivando con exhaustividad - a través de sofisticados algoritmos- patrones de intereses. Esto no solo genera burbujas filtro o resultados de búsqueda personalizados, sino que además altera y configura nuestros espacios de "realidad" virtual (Pariser, 2017).

"Se trata de un recurso ubicuo e inabarcable para el ciudadano de a pie, controlado por instancias, corporaciones y redes políticas, económicas y comerciales cada vez más globales y poderosas cuyos intereses pueden no ser coincidentes, ni siquiera compatibles, con las exigencias de la calidad epistémica que requiere el desarrollo autónomo de los individuos, grupos o comunidades humanas" (Pérez Gómez, 2017, p. 11).

Las transformaciones sociales mencionadas invitan a reflexionar sobre las necesidades educativas de las nuevas generaciones, especialmente en el campo de la formación inicial docente, cuya influencia será decisiva en la renovación pedagógica de las escuelas.

Actualmente, cohabitan en la universidad nativos digitales y procesos anacrónicos de enseñanza, aprendizaje y evaluación. Es decir, un sistema educativo anclado en la enseñanza tradicional, ocupado por jóvenes que han crecido bajo el influjo audiovisual y de las redes sociales, con un acceso inmediato a la información y un contexto sobre estimulado, donde la palabra da paso a la imagen, el concepto a la emoción y el 
proyecto a la satisfacción inminente. Forman parte, sin ningún intermediario que los ayude a cuestionar, analizar y gestionar la información, de una realidad superficial, multisensorial y secuencial que filtra, y "tiende a amplificar de forma drástica el sesgo de confirmación que envuelve las interacciones digitales de los individuos en una ecochamber que condiciona las posibilidades de pensar, decidir, crear e innovar" (Pérez Gómez, 2017, p.32).

No obstante, como señala García Aretio (2019): "el nativo digital no nace digital”, se hace. No nace con habilidades para la selección y filtro de la búsqueda ni el procesamiento de la información, no nace entendiendo el uso ético y seguro de las tecnologías" (p. 16). Por esa razón, resulta fundamental introducir, en los entornos actuales de formación, las herramientas que el alumnado utiliza con mayor frecuencia en su vida cotidiana (Romero, Castellón, López-Pástor y Fraile, 2017). Asimismo, es necesario repensar cualitativamente los procesos educativos para el desarrollo de sistemas de conocimiento y acción más complejos, puestos al servicio del propio proyecto vital (Darling-Hammond, 2010; Pérez Gómez, 2012), logrando así el impulso de recursos y capacidades cognitivas y socioemocionales de orden superior, lo que, según Pérez Gómez (2017) favorecería el tránsito de la información a la sabiduría (p.11).

Downes (2008) y Siemens (2005) también insisten en la necesidad de incluir los medios digitales en la ecuación de la educación actual, pero no de cualquier modo. Se trata de una decisión inevitable y más allá del debate, aparece el dilema de cómo se construye un nuevo escenario no reproductivo de sistemas trasnochados donde se tejan los procesos de aprendizajes con estas fuentes multidireccionales de información. Esto requiere recoger ideas del cognitivismo, entendido, no solo, como lo que sucede cuando nos detenemos a contemplar el mundo e intentamos comprenderlo, sino cuando entendemos que conocer es participar (Weber y Varela 2002; Gross \& Thompson, 2007), el constructivismo donde el alumnado es protagonista de la adquisición de su propio conocimiento $\mathrm{y}$, en su versión más actual, el conectivismo que entiende el aprendizaje como algo caótico, continuo, complejo, de conexión especializada y certeza continua que ocurre en el interior de un ambiente nebuloso de elementos cambiantes, los cuales no están enteramente bajo el control del individuo.

De un modo u otro, la nueva forma de conectarnos con el mundo supone todo un reto para el sistema educativo actual ya que no solo modifica el papel de los profesores o cuestiona la estructura y el sentido de la escuela (Gimeno, 2013), sino que insta a redefinir la educación, especialmente en el ámbito universitario, donde en el curso 2016-2017 se graduaron en España 27.317 maestros/as de grado de Educación Infantil y Primaria (Ministerio de Educación, Cultura y Deporte, 2018).

En este sentido, la formación del profesorado como agente fundamental para los procesos de cambio en los escenarios educativos presentes y futuros se convierte en un espacio urgente de transformación e investigación educativa.

\subsection{La formación inicial del profesorado, una transformación inevitable}

La incorporación española al Espacio Europeo de Educación Superior (EEES) ha impulsado el desarrollo de prácticas innovadoras en las Facultades de Educación, en 
muchos casos, apoyadas por los medios digitales. El propósito es favorecer el desarrollo de las nuevas competencias profesionales docentes definidas como sistemas complejos de reflexión y acción que se sostienen, según Pérez Gómez (2012), por dos principios fundamentales: la pasión por el saber, a través de la promoción del desarrollo profesional autónomo; y la pasión por ayudar a aprender, diseñando, desarrollando y evaluando contextos de aprendizaje ricos, abiertos y democráticos.

¿Es posible que los medios digitales favorezcan el desarrollo de las competencias anteriormente mencionadas y ayuden a adaptar la formación docente a los nuevos tiempos? ¿Podría facilitar el tránsito de una pedagogía reproductiva a una pedagogía relevante, reflexiva y transformadora? Compartimos con Rué (2013) la existencia de un interesante auge de experiencias educativas novedosas en la formación inicial del profesorado.

Las Tecnologías de la Información y la Comunicación (TIC), así como el uso de software y aplicaciones red juegan un papel importante. Su introducción no siempre implica innovación, pero cada vez se trata de vincular más estos recursos a los procesos de aprendizaje y evaluación, estimulando la participación, la relación, la reflexión y la creatividad entre docentes y estudiantes, como procesos claves para el desarrollo de las competencias profesionales (Romero et al., 2017, Soto, Serván y Caparrós, 2016).

Entre todos estos recursos digitales encontramos las redes sociales virtuales, una forma de ofrecerle al estudiante la oportunidad de manipular su entorno de aprendizaje y de participar activamente en él, conectándose a entornos educativos formales e informales en los que se pueda llevar a cabo un intercambio crítico de conocimientos (Wodzicki et al., 2012). Pero ¿Qué entendemos exactamente por redes sociales virtuales? ¿Qué las diferencia de otros recursos tecnológicos?

\subsection{Las redes sociales virtuales como herramienta de enseñanza-aprendizaje}

El término Red Social se ha convertido en una expresión común en los últimos años que asociamos a plataformas como Twitter o Facebook. No obstante, su significado es más amplio y complejo de lo que pudiera parecer. Los antropólogos británicos Alfred Radcliffe-Brown y Jhon Barnes la definieron como "una estructura social formada por personas o entidades conectadas por algún tipo de relación o interés común" (Ponce, 2012, p. 2).

Con la llegada de la Web 2.0, las redes sociales - ahora virtuales- siguen definiendo y concretando estos intereses en establecer procesos de comunicación, cooperación, amistad y negociación, en un contexto determinado y por tiempo indefinido (Ramírez, Bocarando, García y Otero, 2016).

La facilidad para interactuar, la personalización de contenidos, los vínculos y conectividad, la comunicación en tiempo real o el lenguaje multimedia e hipertextual son algunas de sus principales características. No obstante, según la Comisión Redes Sociales IAB Spain (2017) para que una red social virtual sea considerada como tal, debe cumplir los siguientes requisitos:

- Ser una red de contactos

Mahara como red social y portafolio digital en los nuevos contextos de formación inicial docente. Un estudio de caso. Concepción Muñoz-González y Soto-Gómez. Página 5 de 25 
- Autorizar la creación de un perfil personal

- Ofrecer funcionalidades sociales para interactuar con contenidos (crear, compartir, participar)

En los últimos años, la formación superior de carácter virtual se ha multiplicado. Coexisten cursos online, con iniciativas accesibles, masivas y multiplataformas como por ejemplo los Massive Open Online Course (MOOC), junto con un contexto de formación universitaria que inevitablemente, ha iniciado un proceso de transformación e incorporación de los entornos digitales y, en algunos casos, incorporación de las redes sociales a los procesos de enseñanza y aprendizaje, utilizándolas como herramientas capaces de favorecer la comunicación entre docentes y discentes (Buxarrais, 2016, Roig-Vila, 2016, González, Lleixá y Espuny, 2016). Sin embargo, aunque estas experiencias llegan a ser significativas para los participantes que la desarrollan, aún son bastante puntuales. Compaginar el uso de una herramienta que generalmente se utiliza para el esparcimiento con tareas de índole académica, no es tarea sencilla. En este sentido, estudios recientes indican que los estudiantes tienden a considerar los medios sociales como un espacio informal cuyo uso principal es socializar y donde raramente cumplen la función de entornos de aprendizaje formales (Hershkovizt y Forkosh, 2017).

De ahí nuestro interés por investigar las virtualidades pedagógicas de una herramienta digital que aúne ambas facetas: el carácter educativo, académico o formal y las potencialidades de una verdadera red social.

\subsection{Mahara, una herramienta académica con funcionalidades de red social, blog y portafolio digital}

El desarrollo de la web 2.0 ha favorecido el tráfico de información a través de múltiples servicios en línea. Este impacto también se ha visto reflejado en la actividad científica y académica con la aparición y crecimiento de redes de trabajo como ResearchGate, Academia.edu, Mendeley, My Science Work, Scholar Universe, DivulgaRed, etc.

Sin embargo, la demanda de un espacio personalizable que acompañe el proceso de formación de los estudiantes y que integre las potencialidades de las redes sociales no ha sido convenientemente cubierta. Según las últimas investigaciones, y en términos simplificados, solo tres de cada diez universitarios consideran la posibilidad de empoderamiento que les confiere las redes sociales y quienes así lo estiman, no creen que la universidad les haya ayudado a favorecer sus competencias digitales o pensamiento crítico para hacer frente a la multiplicidad de contenidos que consideran creíbles o distorsionados (Gavilán, Martinez y Fernández, 2017)

En este contexto surge Mahara (del Maorí: pensamiento), un software de código abierto inspirado en la arquitectura modular y extensible de Moodle, que integra un sistema particular de portafolio digital, blog y redes sociales, pudiéndose integrar en un marco de aprendizaje virtual más amplio. Fue desarrollado originalmente por universidades neozelandesas en 2006 y mantenido por Catalyst gracias al apoyo adicional del Ministerio de Educación de Nueva Zelanda y Fundación Mellon de la Open Polytechnic, que ganó un Premio Mellon en 2007 por la colaboración tecnológica. 
En los últimos años, universidades de todo el mundo (Nueva Zelanda, Australia, Reino Unido, España, Canadá...) atraídos por su integración de lo académico y lo social, la compatibilidad con Moodle, la gratuidad y actualización constante por la comunidad, han escogido la plataforma Mahara como espacio y complemento virtual de enseñanzaaprendizaje. La posibilidad para escribir diarios de aprendizaje que reflejen los avances y faciliten el acompañamiento, adjuntar contenidos digitales (imágenes, vídeos, música, documentos), organizarlos de manera personalizada, enviar y recibir retroalimentación constante por parte del profesorado y el alumnado, así como construir un sistema de red social capaz de conectar a sus usuarios y crear comunidades en línea, son algunas de sus principales funcionalidades.

La triple naturaleza de la herramienta (Figura 1) permite utilizar un medio digital común de forma autónoma, con una estructura flexible que da sentido a la formación docente y al mismo tiempo establece vínculos con sus experiencias personales.

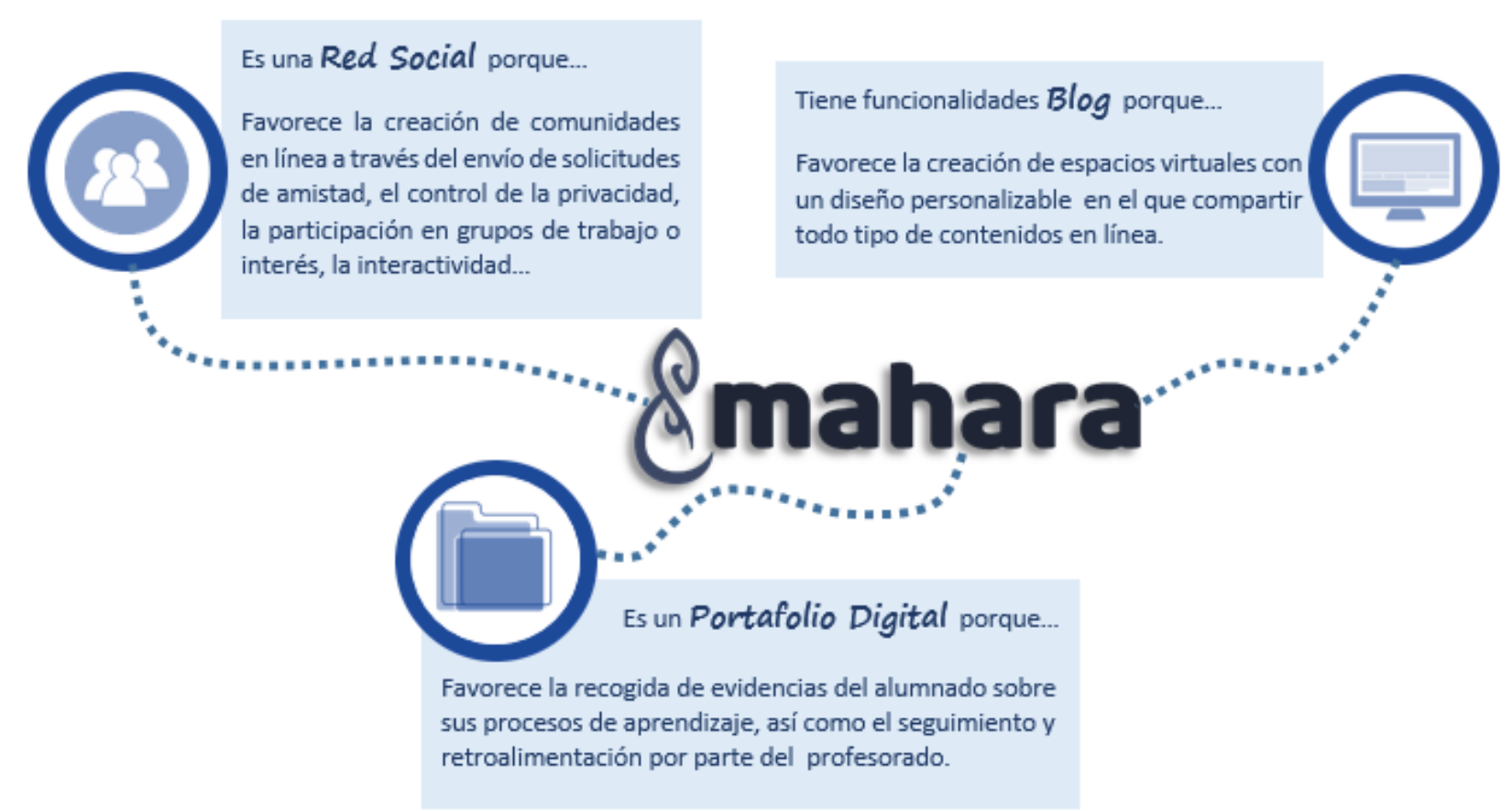

Figura 1. La triple naturaleza de la plataforma Mahara. Fuente: elaboración propia.

Como Red Social, Mahara ayuda al alumnado a establecer relaciones con todos los miembros de la comunidad educativa que participan en la plataforma. Se trata de una manera de favorecer la expresión e interactuar a partir de sus experiencias de forma similar a otras aplicaciones que utilizan en su día a día, pero desde una perspectiva esencialmente académica. Por otro lado, su funcionalidad blog les permite personalizar el diseño de sus páginas, gestionar su organización, incluir en ella todo tipo de elementos audiovisuales, establecer sus propios grupos de trabajo de forma autónoma, así como dejar y responder comentarios. Es un escritorio virtual que ayuda al alumnado a organizar la información y decidir con quién y cómo compartirla.

El uso de Mahara como portafolio digital constituye, quizás, una de sus modalidades más características y utilizadas. Definido como la agrupación de evidencias deliberada sobre el desarrollo y aprendizaje personal, el portafolio educativo cuenta con una extensa literatura que trata de precisar, no sin dificultades, aquello que identifica o no a 
un verdadero portafolio. Entre sus cualidades principales encontramos: la introducción de tareas acompañada de reflexiones bien elaboradas e interconectadas, la participación de los protagonistas en su autoevaluación, la facultad para favorecer la metacognición y autoconocimiento de sus integrantes, así como ser un medio capaz de registrar la evolución y progreso singular del alumnado a corto, medio y largo plazo (Danielson y Abrunty, 1999, Lyons, 2003, Cano, 2005, Martínez, 2009, Rodríguez-Illera, Aguado, Galván y Rubio, 2009 y Pérez Gómez, 2016).

\subsection{Mahara en la Facultad de Educación de la Universidad de Málaga}

Tal y como indica Giné (2009), el alumnado universitario adquiere, construye y utiliza conocimientos sobre el proceso de enseñanza-aprendizaje del cual forma parte (p. 120), por lo que resulta fundamental ofrecerle una experiencia educativa significativa, donde la teoría pueda ser probada a través de la práctica.

En este sentido, durante el curso 2010-2011 tres docentes del Departamento de Didáctica y Organización Escolar de la Universidad de Málaga, aprovechando las transformaciones promovidas por el EEES, prescindieron de los exámenes e iniciaron un proyecto de innovación de carácter interdisciplinar en la formación inicial de maestros y maestras del Grado de Educación Infantil ${ }^{1}$. Su finalidad era estimular la reflexión y el desarrollo de las competencias profesionales de sus estudiantes con metodologías activas y herramientas digitales que les permitieran hacer un seguimiento personalizado de sus aprendizajes. El contexto de enseñanza pretendía facilitar la reconstrucción no solo de los conocimientos, sino también de las creencias, actitudes, emociones y valores que los estudiantes tienen asociados a la enseñanza y a su propio aprendizaje. Para ello, se incorporó el uso de Mahara en la Plataforma Virtual de Enseñanza (Moodle) de la Universidad, denominándola Portafolio UMA (figura 2).
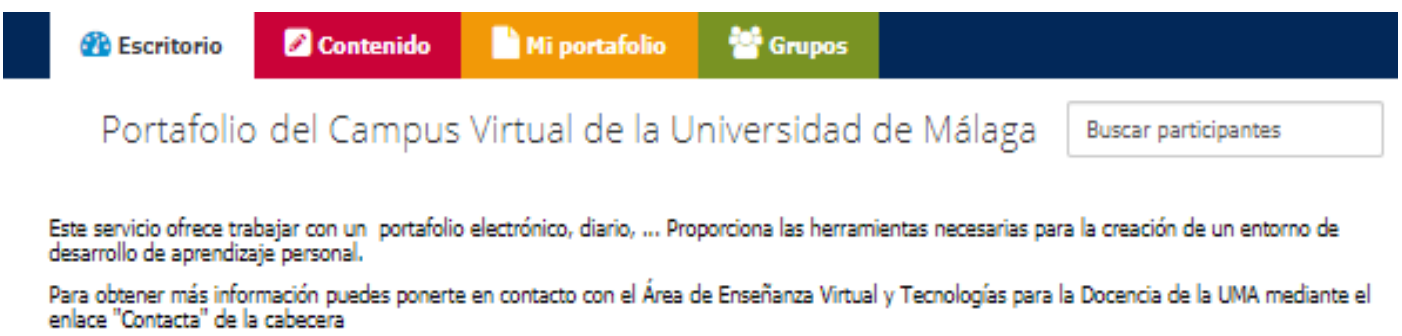

Para obtener más información puedes ponerte en contacto con el Área de Enseñanza Virtual y Tecnologís para la Docencia de la UMA mediante el enlace "Contacta" de la cabecera

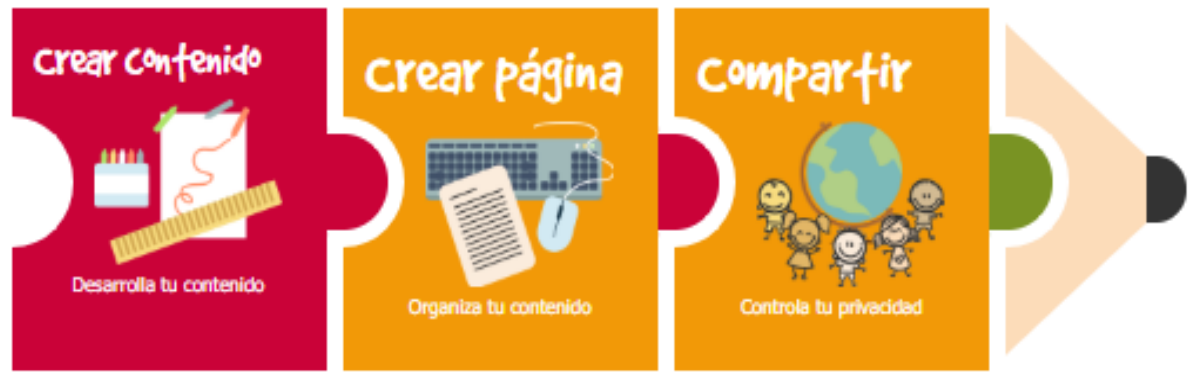

Figura 2. Acceso a Mahara a través del Portafolio UMA. Fuente: Captura de pantalla del escritorio Mahara desde el Campus Virtual de la Universidad de Málaga

Mahara constituía un instrumento de naturaleza dinámica y apto para el desarrollo de procesos reflexivos profundos capaces de estimular - en un contexto metodológico que combina presencialidad, sentido y virtualidad - la reconstrucción del conocimiento

\footnotetext{
${ }^{1}$ Para ampliar los ejes sustantivos de la propuesta se puede consultar la siguiente publicación: Muñoz González, Serván y Soto (2019)
}

Mahara como red social y portafolio digital en los nuevos contextos de formación inicial docente. Un estudio de caso. Concepción Muñoz-González y Soto-Gómez. Página 8 de 25 
práctico de las estudiantes a través de la selección, revisión análisis individual y acompañado de experiencias, relatos, lecturas, diarios, imágenes y vídeos. Evidencias de aprendizaje sugeridas y elegidas para el desarrollo de un pensamiento autónomo, crítico y creativo que promueve un sentido de comunidad académica cooperativo.

Tras ocho años de su incorporación y como consecuencia de los resultados obtenidos (Soto, Serván, y Caparrós, 2016), esta herramienta continúa siendo el eje principal de aprendizaje y evaluación de las asignaturas compartidas por las profesoras que la pusieron en marcha. En este sentido, ha pasado de ser una herramienta experimental a formar parte de los instrumentos habituales de intercambio, enseñanza y aprendizaje de la Facultad de Educación de la Universidad de Málaga, a través de la siguiente propuesta (tabla 1):

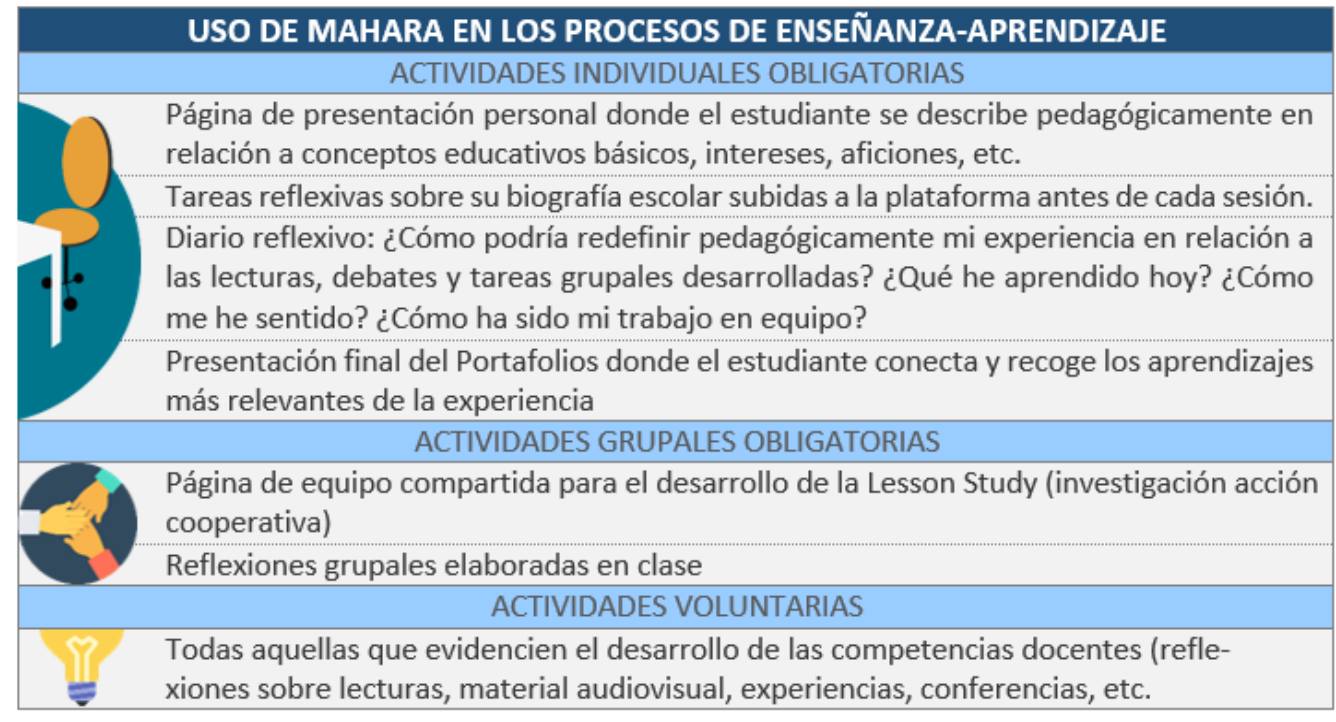

Tabla 1. Actividades desarrolladas en las asignaturas a través de Mahara. Fuente: Elaboración propia

Pero ¿Cómo favorece la herramienta y, específicamente, sus virtualidades digitales una formación docente adaptada a los nuevos tiempos? ¿Cuáles son sus fortalezas y limitaciones?

\section{Metodología}

La presente investigación partió del interés en conocer una herramienta de enseñanza, aprendizaje y evaluación cualitativa coherente con el desarrollo de las competencias docentes y que, al mismo tiempo, fuese congruente con las necesidades educativas de la nueva sociedad digital. El uso de Mahara como portafolio digital con funcionalidad blog y de red social en la formación inicial docente respondía bien a nuestras inquietudes.

\subsection{Enfoque}

Con el fin de comprender las virtualidades y limitaciones pedagógicas de la herramienta Mahara en la formación inicial docente, se empleó el método del estudio de caso desde el que se "persigue la particularización [...] de un caso singular y se llega a conocerlo bien $[. .$.$] no para ver en qué se diferencia de los otros, sino para ver qué es, qué hace"$ (Stake, 2005, p. 20). 
No obstante, profundizar en un caso requiere abordar la complejidad de las relaciones que se establecen, no solo entre los diferentes agentes que participan en él, sino también en la descripción y análisis de las variables que conforman ese tejido de sentido y matices que, sin perder la complejidad, debe estudiarse desde cada uno de los hilos o ejes que lo componen. En este sentido, y en el marco de una metodología de investigación cualitativa, se integraron estrategias de recogida y análisis de información propias de este enfoque, tales como la observación, la entrevista, el grupo focal, el análisis documental a través del portafolio de los estudiantes y un cuestionario abierto, cuyos primeros resultados pueden ser consultados en Muñoz González y Soto (2019) y Muñoz González, Serván y Soto (2019).

En esta ocasión, los resultados de la investigación se centran en la plataforma Mahara como instrumento de comprensión y análisis del Portafolio Digital Educativo. Partiendo del planteamiento del problema recogido en la figura 3, tuvo lugar la recogida de información, así como la posterior triangulación capaz de dotar de rigor y contraste al estudio de casos, tal y como se indica en el apartado 2.4., focalizado en el procedimiento de análisis.

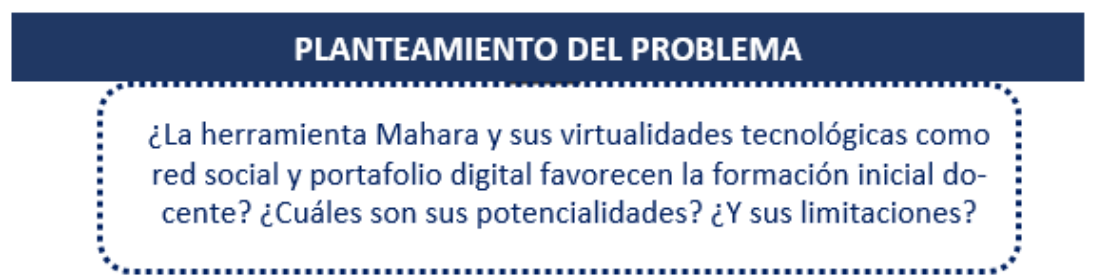

Figura 3. Preguntas claves del planteamiento del problema. Fuente: Elaboración propia

\subsection{Población y muestra}

La investigación que nos atañe tuvo una duración de cuatro años, iniciándose en la Facultad de Ciencias de la Educación de la Universidad de Málaga durante el curso 2015-2016 y finalizando el curso 2018-2019. Específicamente, se desarrolló en un grupo de 60 estudiantes de primer año del grado de Educación Infantil, con el propósito de conocer una propuesta metodológica basada en la Lesson Study, el constructivismo y el Aprendizaje y Servicio, donde la red social y portafolio digital Mahara constituía una piedra angular de todo el proceso, a través de tres asignaturas que funcionaban en coordinación: Didáctica de la educación infantil, Organización de la escuela infantil y Hacia una escuela inclusiva.

Dicha experiencia la iniciaron tres docentes el curso 2010/2011, a la que se incorporó otra más en el curso 2015/2016, diseñando y desarrollando de forma interdisciplinar y cooperativa las tres materias anteriormente mencionadas.

Tal y como recoge en la figura 4, la muestra del estudio de caso fue de 72 participantes, comprendiendo el total de estudiantes del aula (G1) y las 4 docentes (G3: D1...D4), dos estudiantes específicos de este grupo, elegidos por su continuidad en el uso de la herramienta en años posteriores (G2: E1 y E2) y 8 alumnos/as más, de distintas promociones, que habían formado parte de la experiencia con anterioridad y continuaban utilizando Mahara como herramienta de aprendizaje (G4: A1...A8). 


\begin{tabular}{|c|c|c|c|}
\hline Sigla & \multicolumn{2}{|l|}{ Correspondencia } & № de participantes \\
\hline G1 y G2 & \multicolumn{2}{|c|}{ Conjunto y selección de estudiantes del aula } & $58+2$ \\
\hline G3 & \multicolumn{2}{|l|}{ Profesorado } & 4 \\
\hline G4 & \multicolumn{2}{|l|}{ Antiguos/as alumnos/as } & 8 \\
\hline & & Total & 72 \\
\hline
\end{tabular}

Figura 4. Tamaño de la muestra. Fuente: Elaboración propia a partir de los datos de la investigación

\subsection{Instrumentos para la recogida de información}

Las técnicas utilizadas para la recogida de información fueron el seguimiento y la observación no participante de varias sesiones de clase en las asignaturas que formaban parte de la investigación, un cuestionario abierto inicial y final entregado al alumnado, entrevistas individuales a las docentes, entrevistas individuales al estudiantado, grupos focales a estudiantes de distintas promociones que habían experimentado la experiencia en años anteriores y el análisis de carácter longitudinal de los portafolios de dos alumnas del grupo-clase que continuaron utilizando Mahara hasta finalizar el Grado tres años después.

Atendiendo al anonimato y carácter voluntario de las aportaciones, el número de participantes difiere según qué herramienta haya sido utilizada para la recogida, como puede observarse en la tabla 2:

Tabla 2. Correspondencia entre las herramientas, la muestra y la recogida de información. Fuente: Elaboración propia a partir de los datos de la investigación. Recogida, con modificaciones, en Muñoz González y Soto (2019, p. 17) y Muñoz González, Serván y Soto (2019, p. 118)

\begin{tabular}{|c|c|c|c|c|c|c|}
\hline \multicolumn{7}{|c|}{ INSTRUMENTOS DE INVESTIGACIÓN } \\
\hline $\begin{array}{c}\text { Herramienta } \\
\text { utilizada }\end{array}$ & $\begin{array}{c}\text { Características de } \\
\text { la herramienta }\end{array}$ & $\begin{array}{c}\text { Muestra de } \\
\text { participantes }\end{array}$ & $\begin{array}{l}\text { Promoción del } \\
\text { alumnado }\end{array}$ & & $\begin{array}{l}\text { Recogida de } \\
\text { información }\end{array}$ & $\begin{array}{l}\text { Finalidades de } \\
\text { la recogida }\end{array}$ \\
\hline $\begin{array}{c}\text { Diario de } \\
\text { Campo (DC) }\end{array}$ & $\begin{array}{l}\text { Observación ex- } \\
\text { terna, no partici- } \\
\text { pante, escrita, con } \\
\text { apoyo puntual de la } \\
\text { fotografía }\end{array}$ & $\begin{array}{l}60 \text { estudiantes (G1) } \\
4 \text { docentes } \\
\text { (G3: D1...D4) }\end{array}$ & \multirow{11}{*}{ 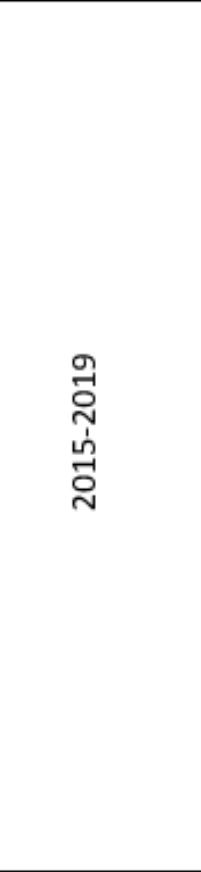 } & 留 & 40 sesiones & $\begin{array}{c}\text { Conocer cómo las } \\
\text { estrategias meto- } \\
\text { dológicas de clase } \\
\text { promueven el uso } \\
\text { de Mahara }\end{array}$ \\
\hline \multirow{2}{*}{$\begin{array}{c}\text { Cuestionarios abier- } \\
\text { tos (CA) }\end{array}$} & \multirow{2}{*}{$\begin{array}{l}\text { Voluntario y anó- } \\
\text { nimo, conformado } \\
\text { por } 12 \text { preguntas de } \\
\text { respuesta libre } \\
\text { sobre el portafolio }\end{array}$} & 29 estudiantes (G1) & & & $\begin{array}{c}\text { Al inicio } \\
22 / 02 / 2016\end{array}$ & \multirow{2}{*}{$\begin{array}{l}\text { Identificar la pre- } \\
\text { disposición inicial } \\
\text { del alumnado y su } \\
\text { evolución en el } \\
\text { uso de Mahara }\end{array}$} \\
\hline & & 50 estudiantes (G1) & & & $\begin{array}{c}\text { Al final } \\
06 / 06 / 2016\end{array}$ & \\
\hline $\begin{array}{c}\text { Análisis de } \\
\text { portafolios (AP) }\end{array}$ & $\begin{array}{l}\text { Lectura analítica, } \\
\text { de búsqueda, } \\
\text { comparación y } \\
\text { confrontación }\end{array}$ & $\begin{array}{l}2 \text { estudiantes } \\
\text { (G2: E1 y E2) }\end{array}$ & & & $\begin{array}{l}\text { Desde: } \\
\text { 2015-2016 } \\
\text { Hasta: } \\
\text { 2018-2019 } \\
\end{array}$ & $\begin{array}{c}\text { Indagar cómo } \\
\text { evoluciona el uso } \\
\text { que se hace de la } \\
\text { herramienta }\end{array}$ \\
\hline \multirow{3}{*}{$\begin{array}{c}\text { Entrevistas } \\
\text { individuales a las do- } \\
\text { centes (ED) }\end{array}$} & \multirow{3}{*}{$\begin{array}{c}\text { Semiestructuradas, } \\
\text { etnográficas, en } \\
\text { profundidad e } \\
\text { inquisitivas } \\
\end{array}$} & \multirow{3}{*}{$\begin{array}{c}3 \text { docentes } \\
\text { (G3: D1, D2 y D3) }\end{array}$} & & \multirow{3}{*}{ 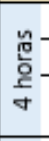 } & (D1): $21 / 06 / 2016$ & \multirow{3}{*}{$\begin{array}{l}\text { Conocer expe- } \\
\text { riencias persona- } \\
\text { les con la herra- } \\
\text { mienta Mahara }\end{array}$} \\
\hline & & & & & (D2): $21 / 07 / 2016$ & \\
\hline & & & & & (D3): 21/07/2016 & \\
\hline \multirow{2}{*}{$\begin{array}{c}\text { Entrevistas } \\
\text { individuales al } \\
\text { estudiantado (EE) }\end{array}$} & \multirow{2}{*}{$\begin{array}{c}\text { Semiestructuradas, } \\
\text { etnográficas, en } \\
\text { profundidad e } \\
\text { inquisitivas } \\
\end{array}$} & \multirow{4}{*}{$\begin{array}{l}2 \text { estudiantes } \\
\text { (G2: E1 y E2) }\end{array}$} & & \multirow{2}{*}{ 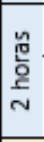 } & (E1): 13/06/2018 & \multirow{2}{*}{$\begin{array}{l}\text { Conocer expe- } \\
\text { riencias persona- } \\
\text { les con la herra- } \\
\text { mienta Mahara }\end{array}$} \\
\hline & & & & & (E2): $27 / 06 / 2018$ & \\
\hline \multirow{2}{*}{$\begin{array}{c}\text { Entrevistas } \\
\text { Individuales finales } \\
\text { al estudiantado (EEF) }\end{array}$} & \multirow{2}{*}{$\begin{array}{l}\text { Semiestructurada, } \\
\text { Figuro-analógica, a } \\
\text { través de metáforas }\end{array}$} & & & & \multirow{2}{*}{$\frac{(E 1): 13 / 12 / 2019}{(E 2): 18 / 10 / 2019}$} & \multirow{2}{*}{$\begin{array}{c}\text { Profundizar en las } \\
\text { categorías ya } \\
\text { establecidas }\end{array}$} \\
\hline & & & & & & \\
\hline \multirow{5}{*}{ Grupos focales (GF) } & \multirow{5}{*}{$\begin{array}{l}\text { Entrevista } \\
\text { exploratoria grupal } \\
\text { y semiestructurada }\end{array}$} & $\begin{array}{l}8 \text { estudiantes } \\
\text { (G4: A1...A8) }\end{array}$ & $2010-2017$ & & Moyo 2016 & \multirow{5}{*}{$\begin{array}{c}\text { Conocer expe- } \\
\text { riencias persona- } \\
\text { les con Mahara de } \\
\text { estudiantes de } \\
\text { antiguas promo- } \\
\text { ciones }\end{array}$} \\
\hline & & $\mathrm{A} 1, \mathrm{~A} 2$ y $\mathrm{A3}$ & $2010-2014$ & \multirow{4}{*}{ 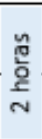 } & \multirow[t]{2}{*}{$18 / 05 / 2016$} & \\
\hline & & A4 & $2011-2015$ & & & \\
\hline & & $A 5$ y $A 6$ & $2012-2016$ & & $25 / 05 / 2016$ & \\
\hline & & A7 y $A 8$ & $2013-2017$ & & & \\
\hline
\end{tabular}




\subsection{Procedimiento de análisis}

Al tratarse de una investigación de carácter cualitativo, los datos recogidos a través de las observaciones, entrevistas, cuestionarios abiertos, grupos focales y lectura de portafolios han sido analizados siguiendo el enfoque interpretativo particular del estudio de casos (Stake, 2005 y Cisterna, 2005) caracterizado por la identificando de variables, el establecimiento de valores, la categorización de los datos, así como su refinamiento, triangulación e interpretación.

Para la reunión y cruce dialéctico de toda la información, nos apoyamos en el software de análisis de datos cualitativo Nvivo que favorece el proceso de codificación, organización y saturación de categorías. En este sentido, tuvimos en cuenta:

- El criterio de pertinencia: que nos permite determinar si los datos se relacionan con la temática de la investigación.

- El criterio de relevancia: que nos ayuda a comprobar si la información se repite y resulta asertiva.

Una vez llegados a este punto, los datos pertinentes y relevantes fueron agrupados, a través de la triangulación, en función de sus coincidencias y divergencias desde la que surgen las categorías, subcategorías y establecimiento de conclusiones.

Asimismo, para asegurar la validez de la investigación, se tuvieron en cuenta tres aspectos fundamentales: a) la observación sistémica y rigurosa del aula foco de la investigación; b) el uso de variadas herramientas y estrategias para la recogida de información y c) la triangulación de métodos y participantes paralelos (Rodríguez, Gil y García, 1999) a través de la combinación de datos y la confrontación de opiniones hasta llegar a su saturación.

\section{Resultados y discusión}

Tras un exhaustivo análisis de la información focalizada en el Portafolio Digital Mahara, se establecieron las categorías finales que aparecen recogidas en la tabla 3. A través de ellas podemos profundizar en los desafíos y potencialidades que implica el uso de la herramienta en un contexto académico de formación docente: 
Tabla 3. Categorías finales del estudio de caso. Fuente: Elaboración propia

\begin{tabular}{|l|}
\hline \multicolumn{1}{c|}{ CATEGORÍAS FINALES } \\
\hline \multicolumn{1}{|c|}{ 3.1. DESAFÍOS DE LA HERRAMIENTA MAHARA } \\
\hline $\begin{array}{l}\text { 3.1.1. Falta de consenso sobre la definición de portafolio educativo: Mahara como } \\
\text { experiencia singular }\end{array}$ \\
\hline $\begin{array}{l}\text { 3.1.2. La metodología didáctica como clave para dotar de sentido pedagógico a la } \\
\text { herramienta: Mahara, una pieza del sistema }\end{array}$ \\
\hline 3.1.3. El uso de la aplicación: Mahara como reto para el alumnado y el profesorado \\
\hline 3.2. POTENCIALIDADES DE LA HERRAMIENTA MAHARA \\
\hline 3.2.1. Mahara transforma al alumnado en protagonista de su aprendizaje \\
\hline 3.2.2. Mahara favorece la competencia digital, la interacción y conectividad \\
\hline 3.2.3. Mahara promueve la reflexión y el autoconocimiento \\
\hline 3.2.4. Mahara enriquece la evaluación educativa \\
\hline
\end{tabular}

Nos encontramos, entonces, que en torno al uso de Mahara como red social y portafolio digital de aprendizaje y evaluación, aparecen elementos desafiantes que suponen cierto grado de dificultad en su aplicabilidad, pero también potencialidades que reconocen los atributos positivos de la herramienta y su valor formativo.

A continuación, compartimos los resultados del estudio, cuyas evidencias aparecen precedidas del siguiente código: (GF.G4 - A1), donde la primera notación corresponde al instrumento de recogida de información (Tabla 2), la segunda al grupo de participantes al que pertenece (Figura 4) y la tercera, al integrante concreto de la muestra (Tabla 2). Cabe destacar que las categorías aquí recogidas poseen una representatividad significativa por parte de cada uno de los agentes o integrantes de la investigación. Es decir, se trata de categorías sustanciales, apoyadas por el profesorado y el alumnado foco de la experiencia, así como los estudiantes de otras promociones que vivenciaron la propuesta en años anteriores.

\subsection{Desafíos de la herramienta Mahara}

Teniendo en cuenta lo anterior, podríamos decir que entre los desafíos de la herramienta se encuentran los siguientes:

\subsubsection{Desconocimiento general hacia el Portafolio Digital Educativo: Mahara como experiencia singular}

Una de las características principales de Mahara es su funcionalidad como Portafolio Digital Educativo. Aunque el alumnado no había oído hablar del portafolio educativo en general y del portafolio digital en particular en etapas académicas anteriores a la universidad, la mayor parte de los protagonistas de la investigación habían tenido experiencias con el portafolio no digitalizado el cuatrimestre anterior. En términos generales, y fruto de estas vivencias, consideraban la herramienta una colección de tareas desconectadas entre sí, elaboradas a través de un procesador de texto que, "acompañadas de una reflexión final" (GF.G4 - A4), debían ser entregadas al docente al concluir la asignatura. Un uso desvirtuado que, como señala el equipo docente, ha proliferado en la universidad en los últimos años: 
(ED.G3 - D1): creo que cada vez hay más docentes que lo usan. Eso es cierto, aquí lo veo cada vez más. Sin embargo, no lo entienden del mismo modo [....] hacen una colección de tareas y entonces, al final, es una locura, porque en lugar de corregir un examen, corrigen un portafolio.

Atendiendo a lo anterior, es posible comprender la tibia y dudosa respuesta del alumnado - recogida en el diario de campo - cuando el primer día de clase se propuso utilizar el Portafolio Digital Educativo como herramienta de enseñanza, aprendizaje y evaluación de manera globalizada en las tres asignaturas:

(DC.G1): La profesora habló de la evaluación y le comentó al alumnado que no habría exámenes, pero sí un trabajo continuado en un portafolio digital a través de la plataforma Mahara. En ella podrían compartir con las docentes y sus compañeros/as las reflexiones y evidencias de su propio aprendizaje apoyándose en texto, imagen, vídeo, enlaces y todo tipo de contenidos digital, así como interactuar, personalizar sus diseños, recibir retroalimentación, crear grupos de trabajo, etc. Algunas estudiantes suspiraron [...] Las profesoras dedicaron buena parte de la mañana a explicar en qué consistiría [...] señalando que no debían desanimarse porque, en base a lo que el alumnado les había contado, el portafolio que se iba a llevar a cabo en las tres asignaturas era bastante diferente al de sus experiencias previas $(15 / 02 / 16)$.

Estas observaciones fueron confirmadas por el cuestionario abierto inicial, donde buena parte del alumnado mostraba un nivel de satisfacción desfavorable o "sensación agridulce" (CA.G1) hacia este tipo de herramienta.

No obstante, resulta notable como, tras la experiencia, el alumnado hacía una clara distinción entre ambas propuestas, destacando Mahara como la más relevante.

(EE.G2 - E1): previamente hice dos portafolios en Words, pero no se parecían en nada al que hicimos en Mahara.

(GF.G4 - A4): introducías todos los trabajos, lo metías todo, hacías una reflexión final y ya está.

(GF.G4 - A3): yo ya de eso ni me acordaba, no los llamo ni portafolios. Era un dossier. Para mí el concepto de portafolio es lo que hacemos en Mahara.

Podríamos decir que estas evidencias ponen de manifiesto el desconocimiento general hacia el Portafolio Digital Educativo, lo que lleva a utilizarlo sin el aprovechamiento de las particularidades y potencialidades otorgadas por lo digital, creando confusión en el alumnado y el profesorado. En este sentido, sería conveniente profundizar en su estudio y comprensión, distinguiendo, además, las características, posibilidades estructurales y componentes que debe poseer una herramienta digital para poder llevarlo a cabo.

\subsubsection{La metodología didáctica como clave para dotar de sentido pedagógico a la herramienta: Mahara, una pieza del sistema}


Uno de los atributos de Mahara es su flexibilidad, lo que le permite transformarse en casi cualquier cosa. Por esa razón, beneficiarse de sus virtualidades como red social y portafolio digital depende, en gran medida, de la metodología que tenga lugar en el aula. Un enfoque tradicional, rígido y reproductivo, restringiría sus potencialidades, en cambio, dentro de un contexto metodológico reflexivo, que da voz a los estudiantes y se promueve la cooperación, la herramienta permite enriquecer la formación.

(ED.G3 - D2): para que Mahara sea un instrumento de aprendizaje es necesario otro enfoque de enseñanza [...] estás utilizando un instrumento tecnológico, sí, pero si no cambias la metodología, estarás haciendo exactamente lo mismo.

(GF.G4 - A1): la que te permite a ti reflexionar es la metodología que se está usando. Si se usa un portafolio, por más digital que sea, nada más que para acumular datos, eso no vale para nada. Tiene que ser que la metodología que esté usando el profesor sea coherente con esa idea de reflexionar, cuestionar las cosas.

(EE.G2 - E1): las sesiones eran innovadoras porque, aunque a veces tuviésemos clases magistrales, aprendíamos los diferentes conceptos a través de experiencias prácticas y no solo en el aula. Aprendíamos con las dinámicas, con nuestras reflexiones en Mahara, con nuestras dudas, nuestros intereses, trabajando en grupo, con lo que proponíamos en la clase de cara a la visita de los niños y niñas [...] si tú estás las cuatro horas escuchando a la profesora que te está hablando, pues luego tienes poco que reflexionar.

\subsubsection{El uso de la aplicación: Mahara como reto para el alumnado y el profesorado}

Las contrariedades para acomodarse a una metodología de aprendizaje que requería de una actitud más participativa y reflexiva que la que habitualmente venían desarrollando se sumaban a las dificultades técnicas. Algunos participantes señalaron que, al principio, el manejo de la nueva herramienta digital les resultó todo un reto (GF.G4 - A5), mientras que a otros les parecía bastante sencillo (GF.G4 - A3). Lo que estaba claro es que nunca antes habían utilizado una herramienta como aquella - con funcionalidad de blog, red social y portafolio digital - en un entorno de formación, lo que, en un principio, era "incómodo" e incluso "frustrante" (CA.G1).

(EE.G2 - E2): al principio era muy agobiante, porque no sabíamos nada. Ni usarlo, ni nada. Era la primera vez que, todos los días por la tarde, tenía que reflexionar sobre lo que había hecho.

(GF.G4 - A1) yo me acuerdo que pensaba $<<$ Pero vamos a ver, ¿No será más fácil coger, como toda la vida, un papel y un lápiz y copiar apuntes? >>

(EE.G2 - E1): la verdad que al principio fue un poco lío, teníamos los tutoriales en vídeo, pero había muchas herramientas que no sabía usar.

(ED.G3 - D3): lo más difícil para mí fue resolver las dudas del alumnado cuando yo también estaba empezando a introducirme en ese tema. Sobre todo las relacionadas con lo que es la herramienta virtual. 
Asimismo, los participantes señalaron que existía cierto temor a que el contenido pudiese llegar a borrarse de la plataforma por "problemas con el servidor", una dificultad que un participante llegó a experimentar, logrando resolver (GF.G4 - A6).

Sin embargo, aunque la "incertidumbre" y el "miedo" (CA.G1) secuestraron inicialmente a los estudiantes, las emociones cambiaron al comprender sus mecanismos $\mathrm{y}$, sobre todo, los principios metodológicos propuestos por las docentes. Finalmente, se apropiaron de la herramienta y la mayoría reconoció preferir ser evaluados a través de la misma que por métodos más convencionales (CA.G1)

(GF.G4 - A6): experimenté un gran cambio, porque pasé de ese punto de detestar la herramienta, hasta ahora que realmente tiene un gran sentido para mí [...] Y ya parece como que la necesitas, que tiene que estar ahí para que el aprendizaje cobre sentido.

(GF.G4 - A7): lo tienes todo, puedes volver a leer lo que hiciste y cómo te mejoras [...] Es una parte tuya y va siendo un reflejo de ti mismo que yo creo que es lo más positivo.

\subsection{Potencialidades de la herramienta Mahara:}

Todo ello nos lleva a reconocer las potencialidades de la herramienta, entre las que encontramos las siguientes:

\subsubsection{Mahara transforma al alumnado en protagonistas de su aprendizaje}

Los participantes señalaron que, en ocasiones, hay estudiantes que asisten a una asignatura para aprobarla "les da igual lo demás y consideran que crecer, van a crecer fuera" (GF.G4 - A6). La enseñanza pasiva desde la que se promueve la memorización de contenidos y que aún se encuentra bastante extendida en la formación universitaria, los lleva a pensar que el aprendizaje relevante comienza "cuando salen de la carrera, no en la propia carrera" (GF.G4 - A8). Sin embargo, la herramienta, a modo de "página web personal y privada" (EE.G2 - E1) desde la que se realiza un seguimiento continuo, transforma al alumnado en auténticos protagonistas de su aprendizaje, impidiendo perpetuar la inacción o indiferencia que solo llama al estudio en la época de exámenes. Depende del alumnado configurar un buen espacio analítico y creativo en el que pueden añadir, no solo sus diarios, trabajos individuales y grupales, sino también, imágenes, vídeos y enlaces a noticias externas, estableciendo relaciones a través de la reflexión.

(ED.G3 - D2): se trata de una herramienta que da voz al alumnado, que facilita la reflexión y que permite que ellos mismos sean capaces de darse cuenta de sus propios progresos.

(EE.G2 - E2): hace fácil recoger todos tus aprendizajes [...] también me ayuda a relacionar los conocimientos que tenía con los nuevos [...] a relacionar los contenidos teóricos que damos en la universidad, con los aspectos prácticos [...] Y así comprendes si realmente lo que está en la ley es lo que se vive en el colegio o lo que estás aprendiendo en la universidad. 
(GF.G4 - A5): el portafolio eres tú y si tú ahora mismo eres esto se va a reflejar.... Si tú ahora mismo estás en ese proceso, se va a ver también.

Esta potencialidad favorece el desarrollo de alguna de las competencias que hablábamos anteriormente, como la creación y mantenimiento de contextos de aprendizajes ricos y flexibles, tanto en lo virtual como en su transposición en las sesiones de clase.

\subsubsection{Mahara favorece el desarrollo de la competencia digital, la conectividad e interacción}

Como red social académica, la herramienta permite crear un perfil personal, enviar notificaciones de amistad, abrir grupos de trabajo, dejar comentarios en línea, así como regular la privacidad de una forma similar a Facebook o Linkedin, a lo que se le añade la posibilidad de personalización estructural propias de aplicaciones como blog. A este respecto, los participantes del estudio de caso destacaron su potencial organizativo y unificador para "recoger todo el proceso en un solo espacio" (EEF.G2 - E1) y una flexibilidad en la configuración que, gracias a la continuidad, les permitió desarrollar la competencia digital:

(GF.G4 - A5): con las tecnologías me llevaba fatal, yo no tenía ni idea. Cuando me dijeron que había que trabajar con el portafolio Mahara, yo me quería morir [...] Una vez le cogí el hilo, para mí se convirtió en la forma más cómoda de trabajar en una asignatura.

(EE.G2 - E1): lo más difícil fue la estética porque no soy muy buena con los ordenadores, entonces, el hecho de poner bonita una página que no sé cuántas herramientas tiene, que no sé qué gama de elección... Al principio no lo pude poner tan estético como el que llevo actualmente porque no tenía las habilidades para ello.

Asimismo, tanto el alumnado como el profesorado señalaron que la plataforma favorece la conectividad e interacción a través del acercamiento síncrono y asíncrono entre estudiante-tutor y estudiante-estudiante. Una manera de que otras personas puedan estar al tanto de lo que piensas (EEF.G2 - E2) y cómo se desarrolla tu recorrido personal:

(GF.G4 - A2): para comunicarnos con el tutor, con los compañeros, nos viene muy bien. Yo me expreso mejor de forma escrita que hablando, esa también es otra ventaja.

(AP.G2 - E2): una de las cosas que más me gustó fue descubrir que algunas de mis compañeras compartían el gusto por las metodologías innovadoras, pues me encanta saber que no estoy loca por pensar que es la mejor forma de educar a los niños y niñas. Al ver que más personas piensan como yo, me anima a desarrollar estos métodos en la escuela.

(EE.G2 - E1): tú decides con quién lo compartes. Si con tu grupo de amigas, con tu grupo de trabajo, si solo con la docente. No es como un foro del campus donde todo el mundo puede pinchar para ver tu trabajo. Puedes elegir quién lo ve, con 
quien lo compartes [...] tienes un feedback por parte de tu tutora y llegábamos a verla como la persona que te cuida, no como la docente que te evalúa.

(ED.G3 - D1): la relación que mantienes con los alumnos es muchísimo más estrecha porque ellos perciben, además, que tú estás ahí para ayudarles.

Gracias al estudio longitudinal fue posible conocer las impresiones reposadas y maduradas del alumnado, tras varios años haciendo uso de la herramienta. Es entonces cuando se advierte, de manera muy particular, la importancia de sus componentes interactivos, sobre los que se posiciona el sentido y valor de la experiencia.

(GF.G4 - A4): yo creo que es muy importante el compartir. El portafolio Mahara, sin nadie que lo lea, ya sea una tutora, una compañera, alguien que te aporte su visión, no sé si le encontraría sentido... Para mí es esencial poder compartirlo y que alguien, cuando te atascas o cuando solo ves una perspectiva, alguien de fuera te abra los ojos, te comente y te haga ver otros puntos de vista

(AP.G1 - E1): siento que gran parte de este trabajo intrapersonal ha sido posible gracias a los diarios, los incidentes críticos y la documentación. Pero no podría haberlo hecho sin compartir mis impresiones en el portafolio [...] sin otros puntos de vista que contrasten con el mío.

Estas evidencias reflejan las potencialidades de Mahara para aprovechar la conectividad e interacción propia de los medios digitales en entornos académicos, al mismo tiempo que se desarrollan las destrezas necesarias para su manejo.

\subsubsection{Mahara promueve la metacognición y el autoconocimiento}

El desarrollo de la "metacognición" (ED.G3 - D3) como capacidad que te permite ser consciente de lo que sabes y de lo que te queda por aprender también fue otro de los atributos destacados de la herramienta. Los participantes hicieron especial hincapié en cómo el uso de Mahara les había ayudado a desarrollar el pensamiento reflexivo y el espíritu crítico "incluso en ámbitos ajenos a la universidad, caminando por la calle" (GF.G4 - A8), así como conocerse a sí mismos, no solo durante la elaboración de sus entradas, sino también, y especialmente, en las relecturas posteriores. Asimismo, gracias a la herramienta, varios estudiantes confesaron haber descubierto facetas personales que les eran desconocidas como la "necesidad de control" (GF.G4 - A7), el "excesivo perfeccionamiento", la "falta de autenticidad" (GF.G4 - A6) o sus "grandes inseguridades" (EE.G2 - E1)

(GF.G4 - A6): llego aquí, me enfrento al portafolio y como que de repente me di cuenta que sí, había sido un buen alumno, pero siempre sin ser yo. Yo era lo que los profesores querían que yo fuese, yo escribía de manera muy recargada, muy pomposa porque necesitaba demostrar que sabía mucho, que era muy listo y de repente te enfrentas a una herramienta en la que te tienes que desnudar y yo tenía muchos miedos de demostrar realmente quién era. 
(GF.G4 - A5): al final te haces consciente de los avances y los progresos que tú has hecho, no solo como docente, sino también como persona, porque todo lo que mejore en cualquier ámbito de nuestra vida, al final has mejorado como persona.

\title{
3.2.4. Mahara enriquece la evaluación y autoevaluación reflexiva
}

Gracias a la herramienta, el profesorado puede percatarse de la evolución del alumnado y hacer retroalimentaciones en línea, invitándolo a reflexionar y a mejorar sus propios procesos, tal y como recoge la figura 5:

\section{Comentarios}

\section{Nombre de usuario}

\begin{abstract}
Hola ya estoy en tu vista intermedia. Es muy gratificante encontrarme con tu trabajo por la riqueza, profundidad e implicación que se percibe, así que quiero felicitarte y animarte a que sigas así, a ver las sorpresas que me depara tu vista final.
\end{abstract}

Si recuerdas el primer post que escribiste en tu diario, el día de la presentación ¿Qué reflexiones podrías haber hecho en esta vista intermedia? Aquel miedo que sentiste y bloqueo ante lo nuevo ¿Cómo ha ido evolucionando? en parte lo comentas, pero sería muy interesante dedicar unas líneas a esa evolución personal tuya y, sobre todo, a los grandes cambios que se han producido en ti, si es que se han producido.

Me gustaría detenerme algo más en un enfoque que enriquecería y complementaría algo más tus reflexiones que tiene que ver con lo que dices: "(...) aprendi algo que considero principal"

¿Cómo dirías que está siendo tu aprendizaje en las asignaturas? ¿De qué tipo? reflexionar a ese nivel indica un nivel superior de reflexión, ya que eres capaz de pensar en ti en relación a un concepto que has interiorizado como para que sea útil. Para ello es fundamental atender a esas características y describir, en torno a un concepto concreto, cómo se han ido desarrollando, poniendo algún ejemplo o evidencia sobre ello.

Por lo demás está muy bien, muy bien expresado y con evidencias tanto de tus diarios como de fotos y videos. También se pueden incorporar lecturas. Tus propósitos de compromiso son muy sensatos y razonables. Si ves que no te queda muy claro lo que intento explicarte, no dudes en consultarme en tutoría o cuando nos veamos en clase. Estoy segura que vas a realizar una vista magnífica al final de curso y espero que esta orientación junto con las que nos quedan, te ayuden a redondearla. Un saludo y enhorabuena.

Figura 5. Comentario docente a un estudiante. Fuente: Portafolio Mahara. Imagen modificada para salvaguardar el anonimato y confidencialidad.

Se trata de un procedimiento muy valorado por el alumnado que, además de anular la sensación de "ser un desconocido, un mero número" (CA.G1), los ayuda a sentir que se valoran sus esfuerzos y progresos:

(EE.G2 - E2): te permite ver desde donde parte cada persona y cómo se va desarrollando [...] yo prefiero que me evalúen a través del portafolio porque, por ejemplo, si hago un examen y tengo un día malo, lo hago mal en el examen. Y si lo hago mal en el examen no demuestro todo lo que sé y puedo suspender la asignatura [...] pero si un día hago una entrada mala en Mahara porque estoy enferma o cualquier otra cosa, al día siguiente lo vuelvo a hacer bien y al final reflejo todos mis aprendizajes, lo que ha sido más significativo para mí. Y la profesora lo valorará, valorará mi progreso, como he ido cambiando... 
(GF.G4 - A7): Mahara refleja el verdadero aprendizaje de una persona [...] al fin y al cabo, puedes ser tú mismo. Por eso, cada perfil, cada portafolio digital, termina siendo diferente porque cada uno vive los aprendizajes y los desarrolla de diferente forma $[\ldots]$ la evaluación será entonces más justa.

Asimismo, Mahara permite que los estudiantes, desde su primer año de carrera, adquieran el hábito de visualizar su evolución, iniciándose en la autoevaluación y calificación (Figura 6), tal y como recoge la siguiente evidencia. Esto favorece el desarrollo de competencias en planificación, desarrollo y evaluación de las enseñanzas.

Respecto a mi evaluación, pienso que me merezco un 8'5, pues considero que me he implicado y esforzado mucho en estas asignaturas, lo que me ha llevado a tener un buen aprendizaje ya que soy capaz de analizar los procesos de enseñanza y aprendizaje en la escuela teniendo en cuenta los diferentes factores analizándolos desde diferentes puntos de vista, y tengo la capacidad de argumentar de forma lógica, personal y coherente, utilizando los conceptos básicos de las tres asignaturas, que es una de las competencias que se pretendia desarrollar, pues pienso que es lo que he hecho en esta página final. Por otra parte, mi actitud en el grupo ha sido buena, pues he tenido la capacidad de colaboración, trabajo en grupo y respeto a la diversidad, otra de las competencias. Sin embargo, me ha faltado desarrollar más actitud individual, pues tendría que haber mostrado una actitud más participativa en clase, aunque esto es debido a la costumbre que todavía me pesa de no poder participar en las clases desde el colegio. También he llevado al día todas las tareas, pues las solia hacer el mismo fin de semana que eran mandadas, y el trabajo individual como las reflexiones, porque aunque, siendo sincera, me falten algunas, siempre he intentado llevarlas al día haciéndolas la misma tarde después de las clases, por lo que con esto he desarrollarlo otra de las competencias, como es la de la capacidad de auto-regulación de mi propio aprendizaje. Por último, decir que donde mejor veo que he aprendido es, remitiéndome a la foto de la introducción, en mis ganas de ser una maestra que abra ventanas para que los niños y niñas puedan mirar, observar, investigar, ver, descubrir, y que abra puertas para entrar y salir, para caminar y correr, y sobre todo, para jugar, para que aprendan jugando, relacionándose e interaccionándose con los demás, siendo respetados y escuchados, es decir, siendo ellos los protagonistas de su propio proceso de aprendizaje, no siendo yo la protagonista en el proceso de todos ellos.

Figura 6. Evidencia de la investigación (AP.G2 - E2). Fuente: Autoevaluación de un integrante de la muestra recogida de su portafolio Mahara.

Pero este proceso no solo enriquece el aprendizaje y autoevaluación de los estudiantes, sino también la de los propios docentes, quienes pueden disponer de evidencias sobre la calidad de sus sesiones, con posibilidades de enmendar los propios "obstáculos y dificultades en la enseñanza" (ED: G3 - D2).

(ED.G3 - D1): cuando hago algo nuevo o importante me gusta revisar el portafolio del alumnado. Por ejemplo, este año, cuando realizamos una asamblea en clase para analizar varias dificultades que estaban surgiendo, tras esa sesión, me leí las entradas de casi todas las alumnas. Le presté especial atención porque deseaba saber si la asamblea se había convertido en el punto de inflexión que buscábamos.

(ED.G3 - D2): Para mí es un instrumento valiosísimo de autoevaluación porque a medida que lo voy revisando, acompañando y analizando, las entradas de las alumnas, sus procesos de aprendizaje, en esa medida, me voy dando cuenta de cuáles son mis propias dificultades.

(ED.G3 - D3): La herramienta te va dando pautas. Te ayuda a saber por dónde van las alumnas y en función de eso puedes ir cambiando la metodología, adaptándola [...]. Te permite escuchar otras voces y hacer un trasvase en la que incluyas sus reflexiones durante la teoría que se trabaja en clase [...] Puedes poner ejemplos de sus experiencias, de fragmentos escritos por ellas que vayas cogiendo 
de sus portafolios [...] Entonces, como escriben el diario después de la clase, puedo leerlo y saber si he cumplido con mis objetivos. Y es algo continuo, no al final de curso, porque, a lo mejor un profesor que haga exámenes se da cuenta de sus errores al final del año, cuando corrige el examen, pero yo me doy cuenta justo después de la clase, cuando aún hay tiempo para abordar la situación.

Una evaluación y autoevaluación reflexiva no solo del aprendizaje, sino también y, sobre todo, para el aprendizaje.

\section{Conclusión}

Esta investigación nos ayuda a comprender cómo Mahara, una plataforma web con funcionalidad de portafolio digital, blog y red social, favorece los procesos de enseñanza, aprendizaje y evaluación en el ámbito de la formación inicial docente, aunando las necesidades de lo académico con aquellas particularidades que tanto nos atraen de las redes sociales y el entorno digital en el que nos desenvolvemos.

Cabe destacar que, como ya hemos señalado, se trata de un artículo que complementa y profundiza en los resultados recogidos en Muñoz González y Soto (2019) — focalizado en los retos del siglo XXI que el portafolio educativo puede ayudar a superar- y en Muñoz González, Serván y Soto (2019) — que expone con detenimiento los aspectos metodológicos de la experiencia concreta desarrollada en el aula durante el curso académico 2015-2016, donde intervenía la Lesson Study y el Aprendizaje y Servicio-; ambos teniendo en cuenta la información recogida en los tres primeros años de investigación.

En esta ocasión, los extractos seleccionados engloban los cuatro años de estudio, incluyendo evidencias que se centran en la herramienta Mahara y sus virtualidades más técnicas. Esto facilita la construcción de una perspectiva significativa sobre un tipo de software en línea que, en relación con una metodología de enseñanza práctica, vivencial, situada y acompañada, promueve el desarrollo de la competencia digital, la metacognición y autoevaluación reflexiva, lo que se ajusta a las demandas de la realidad inmediata, desde la que se impulsa una enseñanza contextualizada capaz de democratizar e implicar al futuro docente en su propio proceso de formación.

A pesar de las dificultades que parecen afrontar los estudiantes y el profesorado cuando comienzan a utilizar la herramienta, ya sea por ese cambio profundo en la cultura del aprendizaje (Muñoz González, Serván y Soto, 2019), como por las cuestiones técnicas aquí recogidas; el estudio pone de manifiesto las potencialidades de Mahara — cuando la metodología lo apoya y el uso de la herramienta es continuado- para provocar procesos que contribuyen a generar aprendizajes de orden superior.

En este sentido, el Portafolio Digital Educativo a través de Mahara, no solo promueve el desarrollo de la responsabilidad, la organización, el pensamiento crítico, la autonomía o la aplicación de conocimientos, que impulsa a reconstruir el pensamiento práctico y romper con esa alarmante desvinculación existente con los propios procesos internos, así como dependencia de la validación externa (Muñoz González y Soto, 2019), sino que además, permite que el alumnado pueda expresarse emocionalmente, aumentando su motivación y autoestima (Muñoz González, Serván y Soto, 2019). Inevitablemente, 
esto ayuda a favorecer el conocimiento de uno mismo y el interés en aquellos procesos educativos implícitos en su formación, así como los incorporados por las redes, lo que conecta el aprendizaje a su propio proyecto vital. Pero, sobre todo, permite vivir una experiencia valiosa que une en un mismo contexto lo digital, lo presencial y el propio aprendizaje como partes indisociables de la realidad, vinculando lo formal y lo personal.

Por lo tanto, y a la luz de las experiencias recogidas en la investigación, podríamos destacar la relevancia de la plataforma Mahara en la formación inicial docente, siempre y cuando sea utilizada a través de un modelo pedagógico activo y participativo. Una combinación capaz de fortalecer el vínculo entre la teoría y la práctica, favorecer el desarrollo de profesionales críticos y reflexivos con el currículum, los medios digitales y el funcionamiento actual de las redes, así como instar a la reflexión en torno a los elementos que conducen a la desinformación, el tribalismo cultural o las burbujas de filtro que mencionábamos en puntos anteriores.

La incorporación de Mahara en universidades de Canadá (Molnar, \& Tan, 2009), Nueva Zelanda (Gerbic, Grey, Moore, \& Bernay, 2009), Australia (Hains, Wakeling, \& Aldred, 2014) o el caso que nos ocupa, nos hablan de un interés cada vez más acusado en transformar la enseñanza-aprendizaje en una experiencia más dinámica, flexible y personalizada, capaz de beneficiarse de las posibilidades de las nuevas tecnologías.

Asimismo, esta investigación empuja a profundizar en otros estudios que describan la influencia tecnológica presente en la formación inicial del profesorado, también en buenas prácticas de evaluación cualitativa en la universidad, así como en las distintas estrategias de enseñanza-aprendizaje que se están llevando a cabo para favorecer el desarrollo de competencias de los futuros profesionales de la educación. Del mismo modo, para fortalecer los resultados obtenidos, podría ser interesante emprender un estudio que analice el ejercicio docente del alumnado egresado que haya participado en esta experiencia, ya que permitiría conocer de qué modo los hábitos y competencias favorecidas por la herramienta Mahara ha influido en su práctica docente.

Las restricciones de este estudio corresponden a las habituales del enfoque cualitativo. Por un lado, la posibilidad de subjetividad, que se ha tratado de eludir a través del uso de variados instrumentos para la recogida y análisis de la información. Por otro lado, la generalización, que debe tratar de evitarse al comprender que los resultados obtenidos atañen a una experiencia y muestra determinada, en un momento y espacio concreto y con una metodología adaptada a dichas prácticas. En este sentido, amplificar estos resultados a distintos grupos en otras situaciones ocasionaría sesgos.

A modo de conclusión, podríamos decir que la herramienta Mahara parece responder bien a esa necesidad de incorporar las potencialidades de las redes sociales al ámbito educativo y adaptar la educación a los nuevos tiempos, favoreciendo la conectividad, la interacción, el desarrollo de la competencia digital y sobre todo, el autoconocimiento.

\section{Agradecimientos}

Al alumnado de Educación Infantil de la Universidad de Málaga que ha participado en la investigación, así como al profesorado implicado en el proyecto foco del estudio de caso. Sin su colaboración, no hubiese sido posible. 
Presentación del artículo: 28 de febrero de 2020

Fecha de aprobación: 9 de marzo de 2020

Fecha de publicación: 31 de marzo de 2020

Concepción Muñoz-González, L., y Soto-Gómez, E. (2020). Mahara como red social y portafolio digital en los nuevos contextos de formación inicial docente. Un estudio de caso. RED. Revista de Educación a Distancia, 62.

http://dx.doi.org/10.6018/red.397021

\section{Financiación}

Esta investigación ha recibido apoyo financiero del Ministerio de Educación y Formación Profesional de España a través de la Beca FPU (Formación del Profesorado Universitario).

\section{Referencias bibliográficas}

Buxarrais, M. R. (2016). Redes sociales y educación. Education in the Knowledge Society, 17(2), 15-20.

Cano, E. (2005). El portafolios del profesorado universitario. Un instrumento para la evaluación y para el desarrollo profesional. Barcelona, España: Octaedro.

Cisterna, F. (2005). Categorización y triangulación como procesos de validación del conocimiento en investigación cualitativa. Theoria, 14, 1, 61-71. Recuperado en: https://bit.ly/2OVbnfc

Danielson, C. y Abrutyn, L. (1999). Una introducción al uso de portafolios en el aula. México: Fondo de Cultura Económica. Recuperado en https://bit.ly/2CPaKZn

Darling-hammond, L. (2010). Evaluating Teacher Effectiveness: How Teacher Performance Assessments can Measure and Improve Teaching. Washington DC: Center for American Progress.

Deloitte Insight. (2019). A technical primer. Recuperado en: https://bit.ly/2kzYvgu

Desjardins, J. (2018). What Happens in an Internet Minute in 2018? Visual Capitalist. Recuperado en: https://bit.ly/2kLWqOl

Downes, S. (2008). An introduction to connective knowledge. Media, Knowledge \& Education: Exploring new Spaces, Relations and Dynamics. In Hug, T. (Ed.) Digital Media Ecologies (pp. 77-102). Innsbruck: Innsbruck University Press

García Aretio, L. (2019). Necesidad de una educación digital en un mundo digital.RIED. Revista Iberoamericana de Educación a Distancia, 22(2), 09-22. DOI: http://dx.doi.org/10.5944/ried.22.2.23911

Gavilán, D., Martínez, G. y Fernández, S. (2017). Universitarios y redes sociales informativas: Escépticos totales, moderados duales o pro-digitales. Comunicar, 53(25), 61-70. DOI: https://doi.org/10.3916/C53-2017-06

Gerbic, P., Grey, A., Moore, W. \& Bernay, R. (2009). Introducing the Mahara eportfolio to student teachers: Teachers perspectives. He Кири, 1(2), 15-19. Recuperado en: https://bit.ly/2ITLCoa

Gimeno, J. (2013). En busca del sentido de la educación. Madrid: Ediciones Morata.

Giné, M. (2009). Cómo mejorar la docencia universitaria: el punto de vista del estudiantado. Revista Complutense de Educación, 20 (2), 117-134. Recuperado en: https://bit.ly/2Kdivkx

Mahara como red social y portafolio digital en los nuevos contextos de formación inicial docente. Un estudio de caso. Concepción Muñoz-González y Soto-Gómez. Página 23 de 25 
González, J., Lleixà, M. y Espuny, C. (2016). Las redes sociales y la educación superior: las actitudes de los estudiantes universitarios hacia el uso educativo de las redes sociales, de nuevo a examen. Education in the Knowledge Society, 17(2), 21-38

Gross, J. y Thompson, R. (2007) Emotion regulation: Conceptual foundations. In J.J. Gross (Ed.), Handbook of emotion regulation. New York: Guilford Press, 3-24

Hershkovizt, A. y Forkosh, A. (2017) La relación profesor-alumno y la comunicación en Facebook: percepciones de los alumnos. Comunicar, 53(25), 91-101. DOI: https://doi.org/10.3916/C53-2017-09

Hains, R., Wakeling, L. \& Aldred, P. (2014). A University-Wide ePortfolio Initiative at Federation University Australia: Software Analysis, Test-to-Production, and Evaluation Phases. International Journal of ePortfolio, 2(4), 143-156. Recuperado en: https://bit.ly/2J9X8z5

IAB Spain. (2017). Estudio Anual de Medios de Comunicación 2017. (https://bit.ly/2ryDr9D) (10-05-2019)

IAB Spain (2019). Estudio Anual de Redes Sociales 2019. (https://bit.ly/2XAaokQ) (10-05-2019)

INFOEMPLEO-ADECCO (2018). Redes Sociales y Mercado de Trabajo. Informe 2016. (https://bit.ly/2lB89Q7) (07-09-2019)

Lyons, N. (Comp.) (2003). El uso de portafolios. Propuestas para un пиеvo profesionalismo docente. Buenos Aires, Argentina: Amorrortu editores S.A.

Martínez, M. J. (2009). El portafolio para el aprendizaje y la evaluación: utilización en el contexto universitario [PDF]. Murcia, España: Universidad de Murcia. Recuperado en: https://bit.ly/2UB66YZ

Ministerio de Educación y Formación Profesional. (2018). Datos y cifras. Curso escolar 2018/2019. Recuperado en: https://bit.ly/2kKFKqr (05-05-2019)

Molnar, T. \& Tan, I. (2009). The utilization of electronic Portfolios (ePortfolios) in the development of teacher. Leader candidates. In T. Bastiaens et al. (Eds.), Proceedings of World Conference on E-Learning in Corporate, Government, Healthcare, and Higher Education (pp. 2965-2969). Chesapeake: AACE.

Muñoz González, L. C., Serván, M. J. y Soto, E. (2019). Las Competencias Docentes y el Portafolio Digital: Crear Espacios de Aprendizaje y Evaluación en la Formación Inicial del Profesorado. Un estudio de casos. Revista Iberoamericana de Evaluación Educativa, 12(2), 111-131. Recuperado en: https://bit.ly/2w8dTpw

Muñoz González, L. C. y Soto, E. (2019). El portafolio digital ¿Una herramienta para aprender a ser docentes críticos?: Un estudio de casos. Actualidades Investigativas en Educación, 19(3), 1-32. Recuperado en: https://bit.ly/39y2Fci

Pariser, E. (2017). El filtro burbuja: como la web decide lo que leemos y lo que pensamos. Barcelona: Taurus.

Pérez Gómez, A. I. (2012). Educarse en la era digital. Madrid: Morata.

Pérez Gómez, A. I. (Dir.). (2016). El Portafolio Educativo en Educación Superior. Madrid, España: Ediciones Akal S.A.

Pérez Gómez, A. I. (2017). Pedagogía en tiempos de perplejidad. De la información a la sabiduría. Buenos Aires: Homo Sapiens.

Pew Research Center (2015). Social Media Usage: 2005-2015. (https://pewrsr.ch/2Avvap8) (02-03-2019)

Ponce, I. (2012): "Monográfico: Redes Sociales". Observatorio Tecnológico NIPO: 820-10-289-9 (https://bit.ly/1kHn8yS) (20/4/2019)

Mahara como red social y portafolio digital en los nuevos contextos de formación inicial docente. Un estudio de caso. Concepción Muñoz-González y Soto-Gómez. Página 24 de 25 
Izco, E. (2007). Los adolescentes en la planificación de medios. Segmentación y conocimiento del Target. Facultad de Comunicación de la Universidad de Navarra. Tesis doctoral (https://bit.ly/2GRsh5n) (01-02-2019)

Ramírez, J., Bocarando, J., García, T. y Otero, A. (2016): El impacto de la calidad de vida por el uso de redes sociales: estudio de percepción de universitarios de una entidad académica pública. Ciencia Administrativa, 2, 27-40.

Rodríguez, G., Gil, J. y García, E. (1999). Metodología de la investigación cualitativa. Granada, España: Aljibe.

Rodríguez, J. (2019). Primitivos de una nueva era. Cómo nos hemos convertido en homo digitalis. Grupo Planeta. Edición de Kindle

Roig-Vila, R. (ed.). (2016). Tecnología, innovación e investigación en los procesos de enseñanza-aprendizaje. Barcelona: Octaedro, p. 676-683

Rodríguez-Illera, J.L, Aguado, G., Galván, C. y Rubio, M.J. (2009). Portafolios electrónicos para propósitos múltiples: aspectos de diseño, de uso y de evaluación. Revista de Educación a Distancia. Red. Monográfico VIII.

Romero, M., Castellón, F.J, López, V.M. y Fraile, A. (2017). Evaluación formativa, competencias comunicativas y TIC en la formación del profesorado [Formative Assessment, Communication Skills and ICT in Initial Teacher Training]. Comunicar, 52(25), 73-82. DOI: https://doi.org/10.3916/C52-2017-07

Rué, J. (2013) Formación docente en el contexto universitario. Una perspectiva Internacional. Revista de Docencia Universitaria. 11(3). 17-22. Recuperado en: https://bit.ly/2sdHs4h

Siemens, G. (2005). Connectivism: A learning theory for the digital age. International Journal of Instructional Technology \& Distance Learning. 2(1). Recuperado en: https://bit.ly/2KVrhj5

Soto, E., Serván, M.J. Y Caparrós, R. (2016) Otra escuela posible. Claves para reconstruir el conocimiento práctico en el contexto universitario. Infancia. Revista de la Asociación de Maestros Rosa Sensat. 157, 5-16.

Stake, R. E. (2005). Investigación con estudio de casos. Madrid: Ediciones Morata.

W3Techs. Web Technology Surveys (2019). Usage statistics and market share of WordPress for websites (https://bit.ly/2kknAvG) (03-09-2019)

We are social y Hootsuite. (2019). Digital 2019: Essential insights into how people around the world use the internet mobile devices, social media and e-comerce. Recuperado en: https://bit.ly/2OQ9E8x

Weber, A. \& Varela, F. J. (2002) Life after Kant: Natural puposes and the autopoietic foundation of individuality. Phenomenology and the Cognitive Sciences 1, 97125. Recuperado en: https://bit.ly/2IJ6ylU

Wodzicki, K., Scwämmlein, E. \& Moskaliuk, J. (2012). Actually, I want to learn: Study-relate Knowledge exchange on social networking sites. Internet and Higher Education, 15 (1), 9-14. 